\title{
Tools used to measure airway remodelling in research
}

\author{
C. Bergeron*, M.K. Tulic* and Q. Hamid*
}

ABSTRACT: Airway remodelling refers to changes in the airway structure and includes subepithelial fibrosis, increased smooth muscle mass, submucosal gland enlargement, neovascularisation and epithelial alterations. Remodelling is observed in response to chronic injury and is seen not only in asthma but in all airway diseases.

Remodelling is associated with more severe airflow obstruction and airway hyperresponsiveness in asthma; however, the clinical significance of this is still a matter of debate. Research should be pursued to better understand the accurate implication of airway remodelling in disease and its therapeutic modulation.

To allow research in this field, accurate and standardised methods should be utilised to measure airway alterations in disease and following therapy. The standard detection of structural alterations is through direct analyses of airway tissues obtained during a post mortem, surgically or by flexible bronchoscopy. To avoid invasive techniques, other tools have been developed to indirectly measure remodelling, including induced sputum, bronchoalveolar lavage fluid, blood and urine analyses, physiological and radiological assessments, as well as in vitro techniques.

Although of great interest, the exact significance of airway remodelling measurements gained through such indirect techniques is uncertain and further research is needed. Despite their invasive nature, direct methods should be favoured to adequately measure airway remodelling in disease and its modulation by therapy.

KEYWORDS: Airway remodelling, asthma, chronic obstructive pulmonary disease, immunohistochemistry, pathology

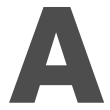
irway remodelling includes subepithelial fibrosis, increased smooth muscle mass, enlargement of glands, neovascularisation and epithelial alterations. Remodelling is not only restricted to the airways but also occurs in a wide range of tissues and organs, including the skin in sclerodermia [1] and wound healing process [1, 2], as well as in the intestine in inflammatory bowel diseases [3, 4]. Remodelling is observed in almost every injured tissue, particularly in tissues that undergo repeated chronic injury. In airway diseases, remodelling is associated with clinical outcomes such as more severe airflow obstruction and airway hyperresponsiveness [5-9]. The clinical significance of airway remodelling is still controversial.
However, targeting airway remodelling with treatment has the potential to decrease severity, to improve control and to prevent disease expression. To better understand the accurate implication of airway remodelling in diseases and its modulation by therapy, more research should be performed. The present manuscript is an overview of the current techniques used to assess

\section{REMODELLING IN AIRWAY DISEASES}

\section{Airway remodelling in asthma}

Airway remodelling in asthma was first described in cases of fatal asthma in 1922 by H.L. Huber and K.K. Koessler (reviewed in [10]). Airway remodelling has been documented in airway remodelling.
AFFILIATIONS

*Meakins-Christie Laboratories, McGill University, Montreal, QC Canada.

\#Division of Cell Biology, Telethon Institute for Child Health Research, Centre for Child Health Research, University of Western Australia, Perth, Australia.

CORRESPONDENCE

Q. Hamid

Meakins-Christie Laboratories

McGill University

3626 St Urbain Street

Montreal

QC

Canada H2X 2P2

Fax: 15143987483

E-mail: qutayba.hamid@mcgill.ca

Received:

February 092006

Accepted after revision:

August 292006

STATEMENT OF INTEREST

None declared. 
not only the large but also in small asthmatic airways [11]. Loss of epithelial integrity [12], thickening of basement membrane [13], subepithelial fibrosis [14], goblet cell and submucosal gland enlargement $[15,16]$, increased smooth muscle mass [15], decreased cartilage integrity [17] and increased airway vascularity are the structural changes that have been documented in the asthmatic airways $[18,19]$. Epithelial alterations in asthma are epithelial fragility and goblet cell hyperplasia. It is still a matter of debate whether epithelial detachment is a real disease phenomenon or simply an artefact of biopsy sampling [12, 15, 20,21]. Subepithelial fibrosis is seen at the level of lamina reticularis and this fibrotic process may extend deeper into the subepithelial layer. Fibrosis is a result of increased deposition of extracellular matrix (ECM) proteins, including collagens I, III and V, fibronectin, tenascin, lumican and biglycan [13, 22-25]. Alterations in smooth muscle layer are hypertrophy, hyperplasia and migration of the smooth muscle cells to the subepithelial area [15, 26, 27]. The airway smooth muscle cells may participate in enhancing inflammation and remodelling through the release of cytokines, chemokines and ECM proteins [28-30]. Vascular alterations include increased size of airway wall vessels and angiogenesis [18]. These structural changes may stem from an ongoing chronic inflammatory process involving the activation of inflammatory cells, including CD4+ T-cells, eosinophils, neutrophils and mast cells [31-35]. The inflammatory mediators that drive this process include cytokines (interleukin (IL)-4, IL-5, IL-9 and IL-13), transforming growth factor (TGF)$\beta$, granulocyte/macrophage-colony stimulating factor, lipid mediators and histamine. Some of these mediators have potent remodelling properties, such as TGF- $\beta$, IL-11 and IL-17 $[5,36,37]$.

\section{Structural alterations in chronic obstructive pulmonary disease}

Airways of patients with chronic obstructive pulmonary disease (COPD) are characterised by squamous cell metaplasia, loss of epithelial cilia, goblet cell hyperplasia, mucus gland enlargement and smooth muscle hypertrophy [38-41], with increases in smooth muscle mass more predominant in smaller than larger airways [42]. Airway wall fibrosis and stenotic lesions are also observed in the small airways [43] and imbalance between profibrotic proteases and protective antiproteases has been implicated in the development of emphysema [44]. Normally, basement membrane thickening is not characteristic of airway remodelling in COPD patients, although it has been reported in a subgroup of COPD patients who have a predominant eosinophilic inflammatory profile [45].
Angiogenesis is also observed in COPD airways [46]. In COPD, inflammation is characterised by increased macrophages, CD8+ T-cells and neutrophils and is largely driven by IL- 8 , tumour necrosis factor- $\alpha$, leukotriene (LT) $\mathrm{B}_{4}$ and TGF- $\beta$ [39, 47-53]. Many, if not all, of these structural changes in the COPD lungs can be attributed to direct injury and inflammation from cigarette-smoke components.

\section{Structural alterations in other airway diseases \\ Bronchiectasis}

Bronchiectasis refers to an abnormal dilatation of the bronchi attributed to airway wall destruction strongly related to postinfectious processes. In bronchiectasis, destruction of bronchial cartilage and smooth muscle layer, bronchial ulceration and obstruction of airways by granulomas are common [54]. Otherwise, little is known on detailed airway abnormalities.

\section{Cystic fibrosis}

Cystic fibrosis (CF) is a genetic disorder involving mutations of the CF transmembrane regulator gene. In the CF lung, bronchiectasis, bronchioloectasis and fibrotic changes are often seen. The structural alterations characterising the CF airways include goblet cell and submucosal gland extension to bronchioles and greater height of the epithelium. Loss of cartilage [55], excessive angiogenesis [56] and increased thickness of inner wall and smooth muscle areas in peripheral airways is also observed [57]. A dense fibrous deposition of collagens I and III, tenascin and elastin is reported in the bronchial wall [58]. CF airways are infiltrated with neutrophils, as well as B- and T-cells [59]. IL-8, a neutrophil chemoattractant, and $\mathrm{LTB}_{4}$ are the main inflammatory mediators in CF [60].

As summarised in table 1, most of these structural changes are not characteristic of one specific airway disease, but are shared by all airway diseases. These similarities suggest that the excessive repair process in the human airway is a common way in which to resolve chronic miscellaneous injuries.

\section{METHODS FOR ASSESSMENT OF AIRWAY REMODELLING}

Table 2 presents the tools used in the methods of assessing airway remodelling discussed in the following sections. Direct assessment of remodelling and Indirect assessment of remodelling.

\section{Direct assessment of remodelling: airway tissues}

Post mortem and surgical lung specimens

Pathological features of airway disease were first described in lung specimens obtained by surgery or autopsy. Surgical

TABLE 1 Features of airway remodelling in airway disease

Epithelial alteration

RBM thickness

Subepithelial fibrosis

Mucus gland hyperplasia

++
++
++

Smooth muscle mass
Angiogenesis

$\begin{array}{cc}2 & \\ ++ & ++ \\ ++ & + \\ + & +\end{array}$

Each + represents the degree of association with disease. RBM: reticular basement membrane; COPD: chronic obstructive pulmonary disease; CF: cystic fibrosis. 


\begin{tabular}{|c|c|c|c|c|c|}
\hline & Epithelial alteration & ECM deposition & Mucus glands & Smooth muscle mass & Angiogenesis \\
\hline $\begin{array}{l}\text { Lung specimen, } \\
\text { EBB, TBB }\end{array}$ & $H \& E$ & Van Gieson, Sirius Red M-T, IHC & H\&E, PAS & $\begin{array}{l}\mathrm{H} \& \mathrm{E} I \mathrm{HC} \text { for smooth muscle } \\
\alpha \text {-actin }\end{array}$ & $\begin{array}{l}\text { IHC for collagen IV or Von } \\
\text { Willebrand factor }\end{array}$ \\
\hline Blood/urine & NA & Collagen products, MMP/TIMP & NA & NA & ? \\
\hline
\end{tabular}

tissues provide a unique and global view of the pathological features of disease. In the same individual, the pulmonary tree can be studied from central airways to alveoli. Other components such as pulmonary circulation can also be studied. Specimens from autopsies have been instrumental in understanding the cause of fatal asthma [10]. The index designed by REID [61] and characterisation of emphysema subtypes [40, 43] have been established using surgically removed lungs from COPD patients. The discovery that remodelling also occurs in the distal airways and alveoli in asthma and COPD was based on studies using post mortem lung tissues. An increase in airway wall thickening and smooth muscle area was predominant in the distal airway of fatal asthmatics when compared with asthmatics who died from other causes [62]. Recently, the detection of chymase-positive mast cells in the distal airways has been suggested to be protective for lung function in severe asthma [63]. Surgical lung biopsies obtained by thoracotomy or thoracoscopy are the most invasive method to obtain lung/airway tissues. This procedure requires general anaesthesia and hospitalisation and includes a non-negligible risk of complications. For these reasons, surgical biopsies are not performed for research purposes. However, the unused lung specimen following pathological assessment for a medical condition can be used for research and many centres are now building tissue banks to collect, preserve and allocate these tissues for future research. Major limitations of post mortem and surgical tissues are that samples represent a severe stage of the disease, which has lead to death or surgery. There is also a less accurate knowledge of past medical history, an inability to perform physiological tests, the inapplicability to therapeutic studies and the presence of an underlying lung disease requiring surgical intervention (in most cases lung cancer). Nevertheless, these post mortem or surgical specimens allow a unique and overall understanding of the pathogenesis of airway diseases.

\section{Endobronchial biopsies}

Endobronchial biopsies (EBB) performed under flexible bronchoscopy are widely used in research today and are the standard approach to studying airway remodelling in diseases $[64,65]$. Flexible bronchoscopy is a minimally invasive way to obtain central airway specimens. Histological analyses of these small pieces of airway tissue allow the identification of pathological changes amongst various diseases. EBB are also used to assess potential therapeutic effects in pharmacological studies. Technical and research aspects of EBB have been very well detailed in a recent publication by experts from the Endobronchial Biopsy Workshop [66]. In contrast to surgical tissues, EBB do not allow the study of the entire thickness of the airway and, therefore, results must be interpreted with this limitation. EBB allow the assessment of the remodelling to large airways only. Bronchoscopy units are accessible in most hospitals. EBB are easy to perform by well-trained respirologists, well tolerated by research subjects and can be repeated after challenge, treatment or during exacerbation. EBB have a significantly lower complication rate when compared with transbronchial biopsies.

\section{Transbronchial biopsies}

Transbronchial biopsies (TBB) are also performed under flexible bronchoscopy but sample the distal lung, including the distal airway wall and the alveolar tissues. Very few studies to date have been performed using transbronchial tissue $[63,67,68]$. The primary reason for limited studies is the concern about major complications, such as bleeding and pneumothorax. The pathogenesis of disease can be studied to a similar extent with TBB as with EBB; however, the success rate of obtaining a distal airway wall during TBB sampling is only $\sim 30-50 \%$ per biopsy [66]. To bypass this low success rate, multiple biopsies need to be sampled, usually four to eight, but this is followed by an increased risk of complications. BALZAR et al. [69] demonstrated a similar inflammatory profile in the lungs of asthmatics using TBB and surgically obtained distal airways. Like EBB, TBB can be performed before and after treatment. Using TBB, the present authors recently demonstrated that remodelling can be assessed in distal airways of asthmatics and, furthermore, described the effect of inhaled corticosteroids (ICS) on inflammation and remodelling $[67,70]$. TBB are an interesting tool to study distal airway involvement and therapeutic agents that target distal airways. The major limitations of TBB in airway remodelling research are the underlying risk of major complications related to the procedure itself and the difficulty in obtaining an adequate sample that contains distal airways.

Techniques for the assessment of remodelling in tissue The standard assessment of remodelling is by histological examination of airway tissues. Tissue processing, visualisation 

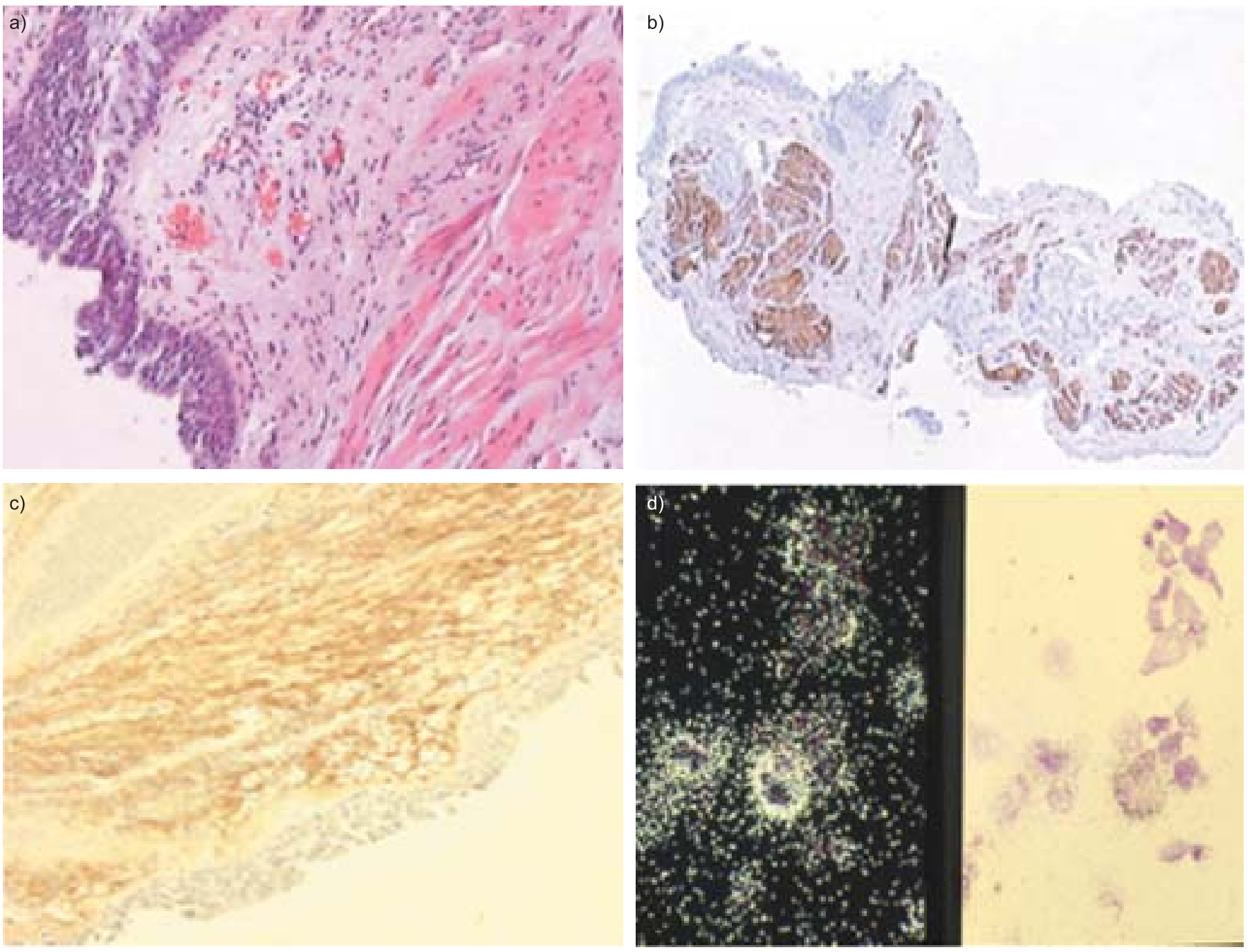

FIGURE 1. Examples of airway remodelling assessment in asthma and chronic obstructive pulmonary disease (COPD) using endobronchial biopsy tissue. a) Haematoxylin and eosin staining, allowing general morphology assessment of airway wall in COPD. b) Immunocytochemistry for smooth muscle $\alpha$-actin (brown) in asthma. c) Immunocytochemistry for subepithelial collagen III fibres (brown) in asthma. d) In situ hybridisation for transforming growth factor (TGF)- $\beta$ illustrating inflammatory cells expressing TGF- $\beta$ mRNA; a positive signal appears bright white under dark field.

methods and quantification are all described in detail by JEFFERY et al. [66]. In brief, post mortem or surgical specimens, EBB and TBB need to be preserved following resection to allow future tissue analysis. Tissues are commonly preserved frozen or embedded in paraffin. Paraffin-embedded tissues show a better preservation of the airway wall morphology and are favoured for remodelling studies. Some remodelling measurements by electron microscopy have been proven to be very helpful in assessing the details of the subepithelial fibrosis and smooth muscle hyperplasia [24]. Airway remodelling is evaluated after histochemical (fig. 1a) and immunohistochemical (fig. $1 \mathrm{~b}$ and c) staining. In general, the assessment of tissue structure is performed with haematoxylin and eosin staining on paraffin or frozen tissues. Sirius red, van Gieson or Masson-Trichrome stain the total collagen. Periodic-acid shiff staining is used to visualise the mucus glands. Immunohistochemistry allows detection of specific proteins thought to be involved in remodelling in the tissues such as ECM proteins
$[13,23]$. Moreover, specific antibodies directed against profibrotic cytokines can also be used. After staining, the slides are analysed under light microscopy. The results are usually expressed as the number of positive cells per area or the area occupied by the specific ECM component (or other) on the total area of the biopsy. The signal detected by immunohistochemistry reflects the tissue expression of proteins. mRNA expression of profibrotic cytokines can also be detected in tissues by in situ hybridisation. (fig. 1d). mRNA can be extracted from total tissues or from specific tissue areas by laser microdissection and then processed to study the expression of gene related to remodelling through Northern blot, real-time PCR following reverse transcription of mRNA or microarrays.

\section{Indirect assessment of remodelling: body fluids}

Bronchoalveolar lavage

Bronchoalveolar lavage (BAL) is performed under flexible bronchoscopy and can be obtained at the same time as EBB. 
BAL is routinely used to study cellular composition and to measure the levels of cytokines/chemokines in the distal airway and alveoli. However, individual components of the distal airway and alveolar compartments cannot be differentiated. The cellular component mainly represents the luminal inflammatory cells and some bronchial epithelial cells. An excess of bronchial epithelial cells in BAL is suggestive of epithelial fragility as commonly observed in asthma. Such analysis of the BAL content during health and disease or before and after treatment/ challenge can compliment airway wall analysis. In fact, some inflammatory cells, such as neutrophils, are found more easily in the airway lumen whereas others, like lymphocytes, are mostly identified in the tissue. As airway remodelling occurs in the tissue, BAL analysis is not the optimal tool with which to study remodelling but serves only as an indirect marker of the remodelling and inflammatory processes that may be going on. Many mediators, including procollagen degradation and synthesis products, matrix metalloproteases (MMP) and tissue inhibitor of metalloproteases (TIMP) as well as profibrotic cytokines, can be quantified in BAL. MMP-9 and TIMP-1 have successfully been quantified and their activity assessed in BAL fluid of asthmatic subjects [71]. Elevated MMP-9 activity is detected in severe asthmatics and asthmatics with mucus hypersecretion, which may suggest a higher turnover of the ECM in the injured airways. In comparison to TBB, BAL fluid sampling is a low-risk procedure to study the distal airway and is well tolerated by subjects with minor complications such as mild fever. The limitations of studying airway remodelling using BAL fluid are: 1) the lack of discrimination between the distal airways and the alveoli; 2) both indirect and limited assessment of remodelling to some soluble markers related to ECM production and degradation; and 3) the inherent inconsistency in the withdrawn BAL volume and also the dilution factor.

\section{Induced sputum}

Hypertonic saline-induced sputum is a relatively noninvasive and easy technique to perform. It is commonly used to evaluate airway inflammation in the central airway. Soluble remodelling-associated proteins, such as procollagen synthesis peptides, MMPs, TIMPs and cytokines, can be detected in the sputum supernatants. Furthermore, induced sputum samples can be obtained before and after specific allergen challenge and/or therapeutic trial. Matrix degradation enzymes and inhibitors have been measured in the induced sputum, such as MMP-2, MMP-9, TIMP-1, TIMP-2, elastase and $\alpha_{1}$-antitrypsin [72-75]. MMP-9 in induced sputum is elevated in severe asthmatics after allergen challenge and is not affected by ICS treatment [75]. This imbalance in the MMP-9/TIMP-1 ratio leads to excessive degradation of ECM proteins that participate in the injury-repair process. The turnover of collagen I can also be indirectly detected in sputum supernatant through the quantification of procollagen type I C-terminal peptide (PICP) and collagen type I C-terminal telopeptide (ICTP). PICP is representative of synthesis of collagen while ICTP reflects collagen degradation. It has been previously reported that PICP in sputum is increased during asthma exacerbation and is correlated with sputum eosinophils [76]. Angiogenic factor, vascular endothelial growth factor (VEGF) and anti-angiogenic endostatin were measured in the sputum supernatants of asthmatics [77], VEGF was found to be elevated in asthmatic sputum suggesting angiogenesis. Sputum processing requires the addition of a reducing mucolytic agent to facilitate the release of the cellular components from the mucus by protein denaturation. However, this significantly reduces the concentration of inflammatory cytokines in the sputum and directly interferes with the immunoassay. This is one of the major limitations in studying mediators in induced sputum. To avoid this limitation, fresh sputum samples without denaturation treatment must be used. Other limitations include the inconsistency of the dilution factor and the yield of obtaining an adequate specimen. However, it is a relatively noninvasive technique, well tolerated and easy to perform, which requires minimal equipment and staff. Sputum induction can also be performed repeatedly, before and after challenge/treatment, and even in children and exacerbated patients. For these reasons, the assessment of airway diseases through induced sputum analyses is gaining popularity in research.

\section{Exhaled breath condensate}

Exhaled breath condensate (EBC) is a noninvasive method of studying airway remodelling and reflects the composition of the fluid lining the airway. Several markers, including hydrogen peroxide, LTs, prostaglandins, isoprostanes, nitric oxide-derived products and hydrogen ions, have been measured successfully in EBC [78]. Such markers mainly reflect the inflammatory status of the airway and have been studied in patients with asthma, COPD or CF $[79,80]$. However, the measurement of mediators within EBC is not very reproducible and the technique needs to be improved [81]. To date, no assessment of airway remodelling has been performed with EBC.

\section{Blood}

Markers of collagen synthesis and degradation can be quantified in blood. Amino-terminal propeptide of type III procollagen and ICTP have been measured in murine blood with liver fibrosis [82], suggesting that such markers can effectively be detected in blood. Other markers such as MMP-9, TIMP-1, cytokines, eotaxin and eosinophil cationicprotein have been measured in the plasma of asthmatics [83, 84]. Increased production and activity of MMP-9 have been reported in the serum of patients with severe asthma, following acute exacerbation. Raised MMP-9 levels in the serum have been proposed as an effective, noninvasive systemic marker of inflammation and airway remodelling in these patients $[83,84]$. Serum TIMP-1 in COPD negatively correlates with airflow obstruction and exacerbation [85]. A low serum MMP-9/TIMP-1 ratio predicts the incomplete reversibility of forced expiratory volume in one second (FEV1) to oral corticosteroids in asthma [86]. Blood sampling is a minimally invasive technique, easy to perform and may be repeated before and after treatment or challenge. However, the assessment of remodelling in blood is not specific to airways and blood markers from other organs can confuse measurements. Furthermore, the absence of a measurable amount of remodelling associated mediators cannot exclude their contribution as most of these proteins are synthesised locally in the lung and are not released in high enough quantities to be measured in the blood.

\section{Urine}

Urine sampling is not a common way to evaluate airway remodelling. In liver disease, the urinary concentration of the 
collagen crosslink, pyridinoline and elastin correlated with liver fibrosis score in biopsy specimens from subjects with cirrhosis [82]. One recent study detected glycosaminoglycans (GAGs), a component of the ECM in asthmatic urine samples [87]. The level of GAGs was reduced after long-term treatment with ICS. Although not specific to airway remodelling, detection of airway remodelling markers in the urine might be an interesting avenue to explore.

\section{Technique for assessment of remodelling in body fluids}

Assessment of remodelling in fluids is quite different to tissues. Specific antibodies against collagens or proteases and antiproteases are also used for protein quantification in fluids. Collagen degradation and synthesis products or MMP and TIMP can be quantified by an enzyme linked-immunosorbent assay or radio-immunoassay. If protein is abundant, Western blot analysis and zymography can be performed. All these techniques detect the protein level in fluids. Inflammatory cells can be assessed by immunocytochemistry and in situ hybridisation for the expression of profibrotic cytokines. mRNA can be extracted from inflammatory cells and then processed to study the gene expression through Northern blot, real-time PCR following reverse transcription of mRNA and microarrays.

\section{Radiological assessment of airway remodelling}

High-resolution computed tomography

It is also possible to assess the airway remodelling by highresolution computed tomography (HRCT) of the thorax. This technique allows the study of the airway lumen and wall dimensions without invasive techniques, which might be useful to grossly assess remodelling in children [88] and in clinical trials [89]. AWADH et al. [90] reported a greater wall thickness with increased asthma severity. Asthmatics with incomplete reversible obstruction have an increased wall thickness, as demonstrated by HRCT, when compared with asthmatics with reversible airway obstruction [91]. However, the observations gathered from HRCT are not as detailed or as informative as histological examination of the tissue and unfortunately there are no studies to date comparing histological and radiological examination of the airways.

\section{Endobronchial ultrasound}

Over the last few years, endobronchial ultrasound (EBUS) has been developed, mainly to allow clinical diagnosis of bronchial carcinoma and targeting nodes sampling in lung cancer staging. However, in 2003, a case report described the measurement of subepithelial thickness/oedema by EBUS in asthmatics in which oedema was reduced by montelukast treatment [92]. One study has validated the measurement of thickening of the airway wall by EBUS, which correlated well to HRCT measurement [93]. Furthermore, a recent study in lung transplant recipients demonstrated that EBUS can discriminate different airway layers and help in the diagnosis of acute lung rejection [94]. Although exciting, EBUS is a relatively invasive technique and histological correlations are actually lacking. Up to now, EBUS cannot discriminate for the different components of the airway wall, such as smooth muscle bundles, and, therefore, the utility of EBUS is limited in airway remodelling research.

\section{Physiological assessment of airway remodelling}

Lung function data has been used to represent airway remodelling. In a longitudinal study from childhood to adulthood, a low post-bronchodilator FEV1/vital capacity (VC) ratio was associated with an accelerated decline in lung function and reduced airway reversibility [95]. This study suggested that a low post-bronchodilator FEV1/VC ratio is representative of airway remodelling and, importantly, that the remodelling process begins early in childhood. Reduced airway distensibility, measured by the change in anatomic dead space with lung volume, has been observed in asthmatics and proposed to reflect airway remodelling [96-98]. This hypothesis was confirmed by one study in which a negative correlation was observed between airway distensibility and reticular basement membrane (RBM) thickness in asthma [99]. From this study, change in dead space with lung volume was reflective of RBM thickness but not other remodelling features. More research needs to be carried out to study the sensitivity of the airway distensibility measurement in asthma severity and treatment response. Airway remodelling has been inconsistently correlated to lung function impairment, but studies using only lung function to assess airway remodelling should be taken with caution.

\section{In vitro remodelling models}

Primary airway structural cells, such as epithelial cells, fibroblasts and smooth muscle cells, can be successfully isolated from human airways. Thus, it is possible to study, in vitro, the fibrogenic and proliferative properties of individual cells following a wide range of stimuli. Recently, researchers have successfully been able to reconstruct airways in vitro using tissue engineering [100]. Such models can be used to study the interaction between structural cells and their response to injury. These reconstructed airways can be physically or chemically injured to study their in vitro repair process.

In summary, airway remodelling is clinically defined as persistent airflow obstruction despite aggressive anti-inflammatory therapies. The standard assessment of remodelling is obtained by surgical lung or airway specimens sampled through flexible bronchoscopy. Flexible bronchoscopy is a minimally invasive technique but requires specialist expertise. Tools have been developed to bypass the biopsy sampling. With indirect analysis of blood, urine or sputum remodelling markers, an insight is gained into the ongoing fibrotic process; however, it is not known whether the fluid variations in collagen products or proteases have significant consequences in the diseased airway walls. These alternative tools, including high-resolution computed tomography, endobronchial ultrasound, lung function measurement and tissue engineering, can be used as screening tools but modulation of airway remodelling will need to be confirmed in airway wall specimens.

\section{REFERENCES}

1 Jorgensen LN. Collagen deposition in the subcutaneous tissue during wound healing in humans: a model evaluation. APMIS Suppl. 2003; 115: 1-56.

2 Philips N, Keller T, Gonzalez S. TGF $\beta$-like regulation of matrix metalloproteinases by anti-transforming growth factor-beta, and anti-transforming growth factor-beta 1 
antibodies in dermal fibroblasts: implications for wound healing. Wound Repair Regen 2004; 12: 53-59.

3 Lawrance IC, Maxwell L, Doe W. Inflammation location, but not type, determines the increase in TGF- $\beta 1$ and IGF1 expression and collagen deposition in IBD intestine. Inflamm Bowel Dis 2001; 7: 16-26.

4 Gao Q, Meijer MJ, Kubben FJ, et al. Expression of matrix metalloproteinases-2 and -9 in intestinal tissue of patients with inflammatory bowel diseases. Dig Liver Dis 2005; 37 : 584-592.

5 Minshall E, Chakir J, Laviolette M, et al. IL-11 expression is increased in severe asthma: association with epithelial cells and eosinophils. J Allergy Clin Immunol 2000; 105: 232-238.

6 Hoshino M, Nakamura Y, Sim JJ. Expression of growth factors and remodelling of the airway wall in bronchial asthma. Thorax 1998; 53: 21-27.

7 Benayoun L, Druilhe A, Dombret MC, Aubier M, Pretolani M. Airway structural alterations selectively associated with severe asthma. Am J Respir Crit Care Med 2003; 167: 1360-1368.

8 Boulet LP, Laviolette M, Turcotte H, et al. Bronchial subepithelial fibrosis correlates with airway responsiveness to methacholine. Chest 1997; 112: 45-52.

9 Jeffery PK, Wardlaw AJ, Nelson FC, Collins JV, Kay AB. Bronchial biopsies in asthma. An ultrastructural, quantitative study and correlation with hyperreactivity. Am Rev Respir Dis 1989; 140: 1745-1753.

10 Redington AE, Howarth PH. Airway wall remodelling in asthma. Thorax 1997; 52: 310-312.

11 James AL, Maxwell PS, Pearce-Pinto G, Elliot JG, Carroll NG. The relationship of reticular basement membrane thickness to airway wall remodelling in asthma. Am J Respir Crit Care Med 2002; 166: 1590-1595.

12 Naylor B. The shedding of the mucosa of the bronchial tree in asthma. Thorax 1962; 17: 69-72.

13 Roche WR, Beasley R, Williams JH, Holgate ST. Subepithelial fibrosis in the bronchi of asthmatics. Lancet 1989; 1: 520-524.

14 Elias JA, Zhu Z, Chupp G, Homer RJ. Airway remodelling in asthma. J Clin Invest 1999; 104: 1001-1006.

15 Carroll N, Elliot J, Morton A, James A. The structure of large and small airways in nonfatal and fatal asthma. Am Rev Respir Dis 1993; 147: 405-410.

16 Aikawa T, Shimura S, Sasaki H, Ebina M, Takishima T. Marked goblet cell hyperplasia with mucus accumulation in the airways of patients who died of severe acute asthma attack. Chest 1992; 101: 916-921.

17 Haraguchi M, Shimura S, Shirato K. Morphometric analysis of bronchial cartilage in chronic obstructive pulmonary disease and bronchial asthma. Am J Respir Crit Care Med 1999; 159: 1005-1013.

$18 \mathrm{Li} \mathrm{X}$, Wilson JW. Increased vascularity of the bronchial mucosa in mild asthma. Am J Respir Crit Care Med 1997; 156: 229-233.

19 Tanaka H, Yamada G, Saikai T, et al. Increased airway vascularity in newly diagnosed asthma using a high-magnification bronchovideoscope. Am J Respir Crit Care Med 2003; 168: 1495-1499.

20 Laitinen LA, Heino M, Laitinen A, Kava T, Haahtela T. Damage of the airway epithelium and bronchial reactivity in patients with asthma. Am Rev Respir Dis 1985; 131: 599-606.

21 Montefort S, Roberts JA, Beasley R, Holgate ST, Roche WR. The site of disruption of the bronchial epithelium in asthmatic and non-asthmatic subjects. Thorax 1992; 47: 499-503.

22 Huang J, Olivenstein R, Taha R, Hamid Q, Ludwig M. Enhanced proteoglycan deposition in the airway wall of atopic asthmatics. Am J Respir Crit Care Med 1999; 160: 725-729.

23 Laitinen A, Altraja A, Kampe M, Linden M, Virtanen I, Laitinen LA. Tenascin is increased in airway basement membrane of asthmatics and decreased by an inhaled steroid. Am J Respir Crit Care Med 1997; 156: 951-958.

24 Wilson JW, Li X. The measurement of reticular basement membrane and submucosal collagen in the asthmatic airway. Clin Exp Allergy 1997; 27: 363-371.

25 Karjalainen EM, Lindqvist A, Laitinen LA, et al. Airway inflammation and basement membrane tenascin in newly diagnosed atopic and nonatopic asthma. Respir Med 2003; 97: 1045-1051.

26 Johnson PR, Burgess JK. Airway smooth muscle and fibroblasts in the pathogenesis of asthma. Curr Allergy Asthma Rep 2004; 4: 102-108.

27 Joubert P, Lajoie-Kadoch S, Labonte I, et al. CCR3 expression and function in asthmatic airway smooth muscle cells. J Immunol 2005; 175: 2702-2708.

28 Panettieri RA Jr. Airway smooth muscle: an immunomodulatory cell. J Allergy Clin Immunol 2002; 110: Suppl. 6, S269-S274.

29 Hakonarson H, Maskeri N, Carter C, Grunstein MM. Regulation of TH1- and TH2-type cytokine expression and action in atopic asthmatic sensitized airway smooth muscle. J Clin Invest 1999; 103: 1077-1087.

30 Johnson PR. Role of human airway smooth muscle in altered extracellular matrix production in asthma. Clin Exp Pharmacol Physiol 2001; 28: 233-236.

31 Metcalfe DD, Baram D, Mekori YA. Mast cells. Physiol Rev 1997; 77: 1033-1079.

32 Kroegel C, Virchow JC Jr, Luttmann W, Walker C, Warner JA. Pulmonary immune cells in health and disease: the eosinophil leukocyte (Part I). Eur Respir J 1994; 7: 519-543.

33 Mosmann TR, Cherwinski H, Bond MW, Giedlin MA, Coffman RL. Two types of murine helper T cell clone. I. Definition according to profiles of lymphokine activities and secreted proteins. J Immunol 1986; 136: 2348-2357.

34 Le Gros G, Ben-Sasson SZ, Seder R, Finkelman FD, Paul WE. Generation of interleukin 4 (IL-4)-producing cells in vivo and in vitro: IL-2 and IL-4 are required for in vitro generation of IL-4-producing cells. J Exp Med 1990; 172: 921-929.

35 Swain SL, Weinberg AD, English M, Huston G. IL-4 directs the development of Th2-like helper effectors. $J$ Immunol 1990; 145: 3796-3806.

36 Molet S, Hamid Q, Davoine F, et al. IL-17 is increased in asthmatic airways and induces human bronchial fibroblasts to produce cytokines. J Allergy Clin Immunol 2001; 108: 430-438.

37 Chakir J, Shannon J, Molet S, et al. Airway remodellingassociated mediators in moderate to severe asthma: effect 
of steroids on TGF-beta, IL-11, IL-17, and type I and type III collagen expression. J Allergy Clin Immunol 2003; 111: 1293-1298.

38 Saetta M, Turato G, Maestrelli P, Mapp CE, Fabbri LM. Cellular and structural bases of chronic obstructive pulmonary disease. Am J Respir Crit Care Med 2001; 163: 1304-1309.

39 Saetta M, Di Stefano A, Turato G, et al. CD8+ Tlymphocytes in peripheral airways of smokers with chronic obstructive pulmonary disease. Am J Respir Crit Care Med 1998; 157: 822-826.

40 Nagai A, West WW, Thurlbeck WM. The National Institutes of Health Intermittent Positive-Pressure Breathing trial: pathology studies. II. Correlation between morphologic findings, clinical findings, and evidence of expiratory air-flow obstruction. Am Rev Respir Dis 1985; 132: 946-953.

41 Maestrelli $P$, Saetta M, Mapp CE, Fabbri LM. Remodelling in response to infection and injury. Airway inflammation and hypersecretion of mucus in smoking subjects with chronic obstructive pulmonary disease. Am J Respir Crit Care Med 2001; 164: S76-S80.

42 Aoshiba K, Nagai A. Differences in airway remodelling between asthma and chronic obstructive pulmonary disease. Clin Rev Allergy Immunol 2004; 27: 35-43.

43 Saetta M, Ghezzo H, Kim WD, et al. Loss of alveolar attachments in smokers. A morphometric correlate of lung function impairment. Am Rev Respir Dis 1985; 132: 894-900.

44 Shapiro SD. Proteinases in chronic obstructive pulmonary disease. Biochem Soc Trans 2002; 30: 98-102.

45 Chanez P, Vignola AM, O'Shaugnessy $\mathrm{T}$, et al. Corticosteroid reversibility in COPD is related to features of asthma. Am J Respir Crit Care Med 1997; 155: 1529-1534.

46 Kranenburg AR, de Boer WI, Alagappan VK, Sterk PJ, Sharma HS. Enhanced bronchial expression of vascular endothelial growth factor and receptors (Flk-1 and Flt-1) in patients with chronic obstructive pulmonary disease. Thorax 2005; 60: 106-113.

47 Turato G, Zuin R, Saetta M. Pathogenesis and pathology of COPD. Respiration 2001; 68: 117-128.

48 Rutgers SR, Timens W, Kaufmann HF, van der Mark TW, Koeter GH, Postma DS. Comparison of induced sputum with bronchial wash, bronchoalveolar lavage and bronchial biopsies in COPD. Eur Respir J 2000; 15: 109-115.

49 Keatings VM, Collins PD, Scott DM, Barnes PJ. Differences in interleukin-8 and tumor necrosis factoralpha in induced sputum from patients with chronic obstructive pulmonary disease or asthma. Am J Respir Crit Care Med 1996; 153: 530-534.

50 Yamamoto C, Yoneda T, Yoshikawa M, et al. Airway inflammation in COPD assessed by sputum levels of interleukin-8. Chest 1997; 112: 505-510.

51 Crooks SW, Bayley DL, Hill SL, Stockley RA. Bronchial inflammation in acute bacterial exacerbations of chronic bronchitis: the role of leukotriene B4. Eur Respir J 2000; 15: 274-280.

52 Beeh KM, Kornmann O, Buhl R, Culpitt SV, Giembycz MA, Barnes PJ. Neutrophil chemotactic activity of sputum from patients with COPD: role of interleukin 8 and leukotriene B4. Chest 2003; 123: 1240-1247.

53 Seggev JS, Thornton WH Jr, Edes TE. Serum leukotriene B4 levels in patients with obstructive pulmonary disease. Chest 1991; 99: 289-291.

54 Fujita J, Ohtsuki Y, Shigeto E, et al. Pathological findings of bronchiectases caused by Mycobacterium avium intracellulare complex. Respir Med 2003; 97: 933-938.

55 Ogrinc G, Kampalath B, Tomashefski JF Jr. Destruction and loss of bronchial cartilage in cystic fibrosis. Hum Pathol 1998; 29: 65-73.

56 McColley SA, Stellmach V, Boas SR, Jain M, Crawford SE. Serum vascular endothelial growth factor is elevated in cystic fibrosis and decreases with treatment of acute pulmonary exacerbation. Am J Respir Crit Care Med 2000; 161: 1877-1880.

57 Tiddens HA, Koopman LP, Lambert RK, et al. Cartilaginous airway wall dimensions and airway resistance in cystic fibrosis lungs. Eur Respir J 2000; 15: 735-742.

58 Durieu I, Peyrol S, Gindre D, Bellon G, Durand DV, Pacheco Y. Subepithelial fibrosis and degradation of the bronchial extracellular matrix in cystic fibrosis. Am J Respir Crit Care Med 1998; 158: 580-588.

59 Hubeau C, Lorenzato M, Couetil JP, et al. Quantitative analysis of inflammatory cells infiltrating the cystic fibrosis airway mucosa. Clin Exp Immunol 2001; 124: 69-76.

60 De Rose V. Mechanisms and markers of airway inflammation in cystic fibrosis. Eur Respir J 2002; 19: 333-340.

61 Reid L. Measurement of the bronchial mucous gland layer: a diagnostic yardstick in chronic bronchitis. Thorax 1960; 15: 132-141.

62 Kuwano K, Bosken CH, Pare PD, Bai TR, Wiggs BR, Hogg JC. Small airways dimensions in asthma and in chronic obstructive pulmonary disease. Am Rev Respir Dis 1993; 148: 1220-1225.

63 Balzar S, Chu HW, Strand M, Wenzel S. Relationship of small airway chymase-positive mast cells and lung function in severe asthma. Am J Respir Crit Care Med 2005; 171: 431-439.

64 Pepe C, Foley S, Shannon J, et al. Differences in airway remodelling between subjects with severe and moderate asthma. J Allergy Clin Immunol 2005; 116: 544-549.

65 Saglani S, Malmstrom K, Pelkonen AS, et al. Airway remodelling and inflammation in symptomatic infants with reversible airflow obstruction. Am J Respir Crit Care Med 2005; 171: 722-727.

66 Jeffery $P$, Holgate S, Wenzel S. Methods for the assessment of endobronchial biopsies in clinical research: application to studies of pathogenesis and the effects of treatment. Am J Respir Crit Care Med 2003; 168: S1-S17.

67 Hauber HP, Gotfried M, Newman K, et al. Effect of HFAflunisolide on peripheral lung inflammation in asthma. $J$ Allergy Clin Immunol 2003; 112: 58-63.

68 Kraft M, Djukanovic R, Wilson S, Holgate ST, Martin RJ. Alveolar tissue inflammation in asthma. Am J Respir Crit Care Med 1996; 154: 1505-1510.

69 Balzar S, Wenzel SE, Chu HW. Transbronchial biopsy as a tool to evaluate small airways in asthma. Eur Respir $J$ 2002; 20: 254-259.

70 Bergeron C, Hauber HP, Gotfried M, et al. Evidence of remodelling in peripheral airways of patients with mild 
to moderate asthma: effect of hydrofluoroalkane-flunisolide. J Allergy Clin Immunol 2005; 116: 983-989.

71 Ko FW, Diba C, Roth M, et al. A comparison of airway and serum matrix metalloproteinase- 9 activity among normal subjects, asthmatic patients, and patients with asthmatic mucus hypersecretion. Chest 2005; 127: 1919-1927.

72 Maisi P, Prikk K, Sepper R, et al. Soluble membrane-type 1 matrix metalloproteinase (MT1-MMP) and gelatinase A (MMP-2) in induced sputum and bronchoalveolar lavage fluid of human bronchial asthma and bronchiectasis. Apmis 2002; 110: 771-782.

73 Suzuki R, Kato T, Miyazaki Y, et al. Matrix metalloproteinases and tissue inhibitors of matrix metalloproteinases in sputum from patients with bronchial asthma. $J$ Asthma 2001; 38: 477-484.

74 Vignola AM, Riccobono L, Mirabella A, et al. Sputum metalloproteinase-9/tissue inhibitor of metalloproteinase1 ratio correlates with airflow obstruction in asthma and chronic bronchitis. Am J Respir Crit Care Med 1998; 158: 1945-1950.

75 Mattos W, Lim S, Russell R, Jatakanon A, Chung KF, Barnes PJ. Matrix metalloproteinase-9 expression in asthma: effect of asthma severity, allergen challenge, and inhaled corticosteroids. Chest 2002; 122: 1543-1552.

76 Nomura A, Uchida Y, Sakamoto T, et al. Increases in collagen type I synthesis in asthma: the role of eosinophils and transforming growth factor-beta. Clin Exp Allergy 2002; 32: 860-865.

77 Asai K, Kanazawa H, Kamoi H, Shiraishi S, Hirata K, Yoshikawa J. Increased levels of vascular endothelial growth factor in induced sputum in asthmatic patients. Clin Exp Allergy 2003; 33: 595-599.

78 Montuschi P. Exhaled breath condensate analysis in patients with COPD. Clin Chim Acta 2005; 356: 22-34.

79 Carpagnano GE, Barnes PJ, Francis J, Wilson N, Bush A, Kharitonov SA. Breath condensate $\mathrm{pH}$ in children with cystic fibrosis and asthma: a new noninvasive marker of airway inflammation? Chest 2004; 125: 2005-2010.

80 Effros RM, Peterson B, Casaburi R, et al. Epithelial lining fluid concentrations in chronic obstructive lung disease patients and normal subjects. J Appl Physiol 2005; 99: 1286-1292.

81 Horvath I, Hunt J, Barnes PJ, et al. Exhaled breath condensate: methodological recommendations and unresolved questions. Eur Respir J 2005; 26: 523-548.

82 Stone PJ. Potential use of collagen and elastin degradation markers for monitoring liver fibrosis in schistosomiasis. Acta Trop 2000; 77: 97-99.

83 Belleguic C, Corbel M, Germain N, et al. Increased release of matrix metalloproteinase- 9 in the plasma of acute severe asthmatic patients. Clin Exp Allergy 2002; 32: 217-223.

84 Matsumoto H, Niimi A, Minakuchi M, Izumi T. Serum eosinophil cationic protein levels measured during exacerbation of asthma: characteristics of patients with low titres. Clin Exp Allergy 2001; 31: 637-643.

85 Higashimoto $Y$, Yamagata $Y$, Iwata T, et al. Increased serum concentrations of tissue inhibitor of metalloproteinase-1 in COPD patients. Eur Respir J 2005; 25: 885-890.

86 Bosse M, Chakir J, Rouabhia M, Boulet LP, Audette M, Laviolette M. Serum matrix metalloproteinase-9: tissue inhibitor of metalloproteinase-1 ratio correlates with steroid responsiveness in moderate to severe asthma. Am J Respir Crit Care Med 1999; 159: 596-602.

87 Priftis KN, Loukopoulou S, Magkou C, Sitaras NM. Increased glycosaminoglycans in the urine of asthmatic children on inhaled corticosteroids. Pediatr Allergy Immunol 2006; 17: 194-198.

88 Marchac V, Emond S, Mamou-Mani T, et al. Thoracic CT in pediatric patients with difficult-to-treat asthma. AJR Am J Roentgenol 2002; 179: 1245-1252.

89 de Jong PA, Nakano Y, et al. Changes in airway dimensions on computed tomography scans of children with cystic fibrosis. Am J Respir Crit Care Med 2005; 172: 218-224.

90 Awadh N, Muller NL, Park CS, Abboud RT, FitzGerald JM. Airway wall thickness in patients with near fatal asthma and control groups: assessment with high resolution computed tomographic scanning. Thorax 1998; 53: 248-253.

91 Hudon C, Turcotte H, Laviolette M, Carrier G, Boulet LP. Characteristics of bronchial asthma with incomplete reversibility of airflow obstruction. Ann Allergy Asthma Immunol 1997; 78: 195-202.

92 Yamasaki A, Tomita K, Sano H, et al. Measuring subepithelial thickness using endobronchial ultrasonography in a patient with asthma: a case report. Lung 2003; 181: 115-120.

93 Shaw TJ, Wakely SL, Peebles CR, et al. Endobronchial ultrasound to assess airway wall thickening: validation in vitro and in vivo. Eur Respir J 2004; 23: 813-817.

94 Irani S, Hess T, Hofer M, et al. Endobronchial ultrasonography for the quantitative assessment of bronchial mural structures in lung transplant recipients. Chest 2006; 129: 349-355.

95 Rasmussen F, Taylor DR, Flannery EM, et al. Risk factors for airway remodelling in asthma manifested by a low postbronchodilator FEV1/vital capacity ratio: a longitudinal population study from childhood to adulthood. Am J Respir Crit Care Med 2002; 165: 1480-1488.

96 Wilson JW, Li X, Pain MC. The lack of distensibility of asthmatic airways. Am Rev Respir Dis 1993; 148: 806-809.

97 Brown NJ, Thorpe CW, Thompson B, et al. A comparison of two methods for measuring airway distensibility: nitrogen washout and the forced oscillation technique. Physiol Meas 2004; 25: 1067-1075.

98 Johns DP, Wilson J, Harding R, Walters EH. Airway distensibility in healthy and asthmatic subjects: effect of lung volume history. J Appl Physiol 2000; 88: 1413-1420.

99 Ward C, Johns DP, Bish R, et al. Reduced airway distensibility, fixed airflow limitation, and airway wall remodelling in asthma. Am J Respir Crit Care Med 2001; 164: 1718-1721.

100 Chakir J, Page N, Hamid Q, Laviolette M, Boulet LP, Rouabhia M. Bronchial mucosa produced by tissue engineering: a new tool to study cellular interactions in asthma. J Allergy Clin Immunol 2001; 107: 36-40. 